\title{
Stoichiometric and Catalytic Deuterium and Tritium Labeling of "Unactivated" Organic Substrates with Cationic Ir(III) Complexes
}

\author{
Marc B. Skaddan,* Cathleen M. Yung, and Robert G. Bergman* \\ Contribution from Pfizer Global Research and Development, Pfizer Inc., 301 Henrietta St., \\ Kalamazoo, Michigan 49007 and Department of Chemistry, University of California and Division of \\ Chemical Sciences, Lawrence Berkeley National Laboratories, Berkeley, California 94720
}

\section{Supporting Information}

I. Procedures and Characterization Data for Stoichiometrically Labeled Compounds

II. Procedures and Characterization Data for Catalytically $d$-Labeled Compounds 
I. Procedures and Characterization Data for Stoichiometrically Labeled Compounds

General (Stoichiometric Reactions). The $\mathrm{CH}_{2} \mathrm{Cl}_{2}$ used for the stoichiometric deuterations/tritiations was purchased from J.T. Baker (BakerDRYTM, catalog No. 9295-10) without further purification. Anhydrous dioxane (Aldrich) was degassed via freeze-pump-thaw (3 cycles). Most substrates were used "as is" from Aldrich, Fluka, or Mallinckrodt. 2-(Methylthio)naphthalene was purchased from Avocado Research Chemicals Ltd. (cat. \#B22368). N-Methylnaphthalene-1-methylamine was purchased from Matrix Scientific (cat. \#007083). The synthesis of $N$-BOC-fluoxetine has been described elsewhere. ${ }^{1,2}$ Mass spectrometer data were collected on a Fisons VG Platform single quadrupole (electrospray), a PerkinElmer Sciex API 150EX (electrospray), a Micromass GCT TOF using a DCI probe (EI, $70 \mathrm{eV}$ ), a Fisons Trio 2000 single quadrupole MS using a DCI probe (EI, 70 $\mathrm{eV}$ ), or a VG 70SE double focusing magnetic sector MS using a direct insertion probe (EI, $70 \mathrm{eV}$ ). Thin-layer chromatography (Analtech scored glass $10 \mathrm{~cm}$ x $20 \mathrm{~cm}$ hard TLC plates, or plastic-backed neutral $\mathrm{Al}_{2} \mathrm{O}_{3}$ ) was used to assess Sep-Pak ${ }^{\circledR}$ purification conditions and to visualize the eluent UV profile. ${ }^{1} \mathrm{H}$ NMR spectra were obtained at 300 or $400 \mathrm{MHz}$ (Bruker) and (where appropriate) are reported in parts per million relative to the incomplete deuteration signal from the NMR solvent. ${ }^{2} \mathrm{H}$ NMR spectra were obtained on a Bruker $500 \mathrm{MHz}$ Avance NMR with a probe optimized for deuterium detection. Chemical shifts are reported in parts per million relative to signals associated with the natural abundance of deuterium in the reference solvent. Deuterium location (as reported in Tables 1 and 2) was performed by correlating deuterium signals with ${ }^{1} \mathrm{H}$ signals. Where applicable, this location was confirmed in the ${ }^{1} \mathrm{H}$ NMR by loss of signal (reduction in relative integration value). Location percentages (as reported in Tables 1 and 2) are approximate and are determined by integration of deuterium signals. HPLC analysis of 1-naphthyl-1-ethanol and 1-allylnaphthalene was performed on an Agilent 1100 LC system, using a Phenomenex Luna C-18(2) $4.6 \times 250$ mm column, $\mathrm{UV}=254 \mathrm{~nm}$, flow $=1.0 \mathrm{ml} / \mathrm{min}$. Radioactivity measurements for $\left[{ }^{3} \mathrm{H}\right]$ warfarin were made on a Packard Tricarb 1900CA liquid scintillation analyzer. 
General Procedure for Stoichiometric H/D exchanges. All manipulations prior to Trisorber manipulations were performed in an $\mathrm{N}_{2}$ dry box. $\mathrm{Cp} * \operatorname{Ir}\left(\mathrm{PMe}_{3}\right) \mathrm{Me}(\mathrm{OTf})$ or $\mathrm{Cp} * \operatorname{Ir}\left(\mathrm{PMe}_{3}\right) \mathrm{MeCl}(4.5-7$ $\mu$ mol, 1.10 equiv) was added to an oven-dried $2.5 \mathrm{ml}$ Trisorber flask with stir bar, then $\operatorname{NaBAr}_{\mathrm{f}}(4.5-7$ $\mu \mathrm{mol}, 1.10$ equiv) was added. The dry mixture was solubilized in $\mathrm{CH}_{2} \mathrm{Cl}_{2}$ (approx. $150 \mu \mathrm{l}$ ), creating a dark orange solution. The flask was capped and stirred vigorously for $10 \mathrm{~min}$. A solution of the substrate (4-6 $\mu \mathrm{mol}, 1$ equiv) in $\mathrm{CH}_{2} \mathrm{Cl}_{2}$ (approx. $150 \mu \mathrm{l}$ ) was added to the Ir solution, and the total volume was brought to exactly $300 \mu$ l. The flask was fitted with an oven-dried 2-way glass stopcock valve (stopcock in closed position), and the reaction mixture was stirred for 20 min at $25{ }^{\circ} \mathrm{C}$. The assembly was removed from the dry box and attached to an IN/US TriSorber ${ }^{\circledR}$ TS-1000 manifold (IN/US Systems Inc., Tampa, FL). The solution was degassed by freeze-pump-thaw (1 cycle). The sensitive volume $\left(\mathrm{V}_{\mathrm{e}}, 3.61 \mathrm{ml}\right)$ was loaded with 760 Torr $\mathrm{D}_{2}(147 \mathrm{umol})$. The sensitive volume was opened to the flask and the reaction was stirred vigorously for $1 \mathrm{~h}$. The reaction mixture was frozen and the excess gas was removed under high vacuum. The apparatus was backfilled with He and removed from the TriSorber ${ }^{\circledR}$ manifold. The reaction mixture was transferred to a $4 \mathrm{ml}$ vial with $\mathrm{MeOH}$, and the solvents were removed under a steady stream of $\mathrm{N}_{2}$. The residue was redissolved in EtOAc/Hexanes and purified by solid phase extraction (SPE) using Sep-Pak ${ }^{\circledR} \mathrm{SiO}_{2}$ classic cartridges (Waters, WAT051910) or, in the case of $N$-methylnaphthalene-1-methylamine, Sep-Pak ${ }^{\circledR}$ neutral $\mathrm{Al}_{2} \mathrm{O}_{3}$ classic cartridges (Waters, WAT051810).

\section{Method for Determining Deuterium Content/Specific Activity of Labeled Molecules}

(Stoichiometric Reactions). The amount of deuterium incorporation was calculated by first measuring the peak heights in the isotopic envelope of the unlabelled substrate standard. An analogous routine was then performed on the purified labeled substrate. The isotopic envelope peak heights from the labeled substrate were then corrected by subtracting out the contribution from the standard (natural abundance). The corrected peak heights for the various isotopes (e.g. $d_{0}, d_{1}$, etc.) were then translated into a percent (peak height of isotope/sum of peak heights from isotopic 
envelope), and these percentages are reported below. The "deuterium equivalents" in the manuscript were calculated by taking the percentage contribution from the individual isotopes, multiplying by the number of deuterium atoms per molecule, then summing the total. For example, for a reaction that gave $40 \% \mathrm{~d}_{0}, 40 \% \mathrm{~d}_{1}$, and $20 \% \mathrm{~d}_{2}$, the "deuterium equivalents" would be: $(0.40 \times 0)+(0.40 \times 1)+$ $(0.20 \times 2)=0.80$ deuterium equivalents. This gives an estimate of the extent of $\mathrm{H}-\mathrm{D}$ exchange. The measurement of specific activity was performed in an analogous fashion, where the fraction corresponding to the tritiated species was multiplied by the requisite maximum specific activity the tritiated molecule could have. For example, a reaction that gave product consisting of $40 \% \mathrm{t}_{0}, 40 \% \mathrm{t}_{1}$, and $20 \% \mathrm{t}_{2}$ would have a specific activity of: $(0.4 \times 28.8 \mathrm{Ci} / \mathrm{mmol})+(0.2 \times 57.6 \mathrm{Ci} / \mathrm{mmol})=23$ $\mathrm{Ci} / \mathrm{mmol}$.

$\left[{ }^{2} \mathbf{H}\right]$-1-Naphthol (Table 1, entry 1). Addition of substrate to the $\mathrm{Ir} / \mathrm{NaBAr}_{\mathrm{f}}$ solution was accompanied by a color change from orange to black within $20 \mathrm{~min}$. The color reverted back to orange upon exposure to $\mathrm{D}_{2}$ gas. SPE solvent system: $20 \%$ EtOAc/Hexanes. Isotope distribution (Fisons VG MS): $27 \% \mathrm{~d}_{0}, 41 \% \mathrm{~d}_{1}, 25 \% \mathrm{~d}_{2}, 7 \% \mathrm{~d}_{3} .{ }^{2} \mathrm{H}$ NMR $\left(\mathrm{CH}_{3} \mathrm{OH}, 77 \mathrm{MHz}\right): \delta 6.80,7.25,7.40$.

$\left[{ }^{2} \mathbf{H}\right]$-Acetanilide (Table 1, entry 2). Addition of substrate to the $\mathrm{Ir} / \mathrm{NaBAr}_{\mathrm{f}}$ solution was accompanied by a color change from dark orange to light orange within $20 \mathrm{~min}$. The color changed to a light yellow-orange upon exposure to $\mathrm{D}_{2}$ gas. SPE solvent system: 20\% EtOAc/Hexanes. Isotope distribution (Fisons VG MS): $28 \% \mathrm{~d}_{0}, 38 \% \mathrm{~d}_{1}, 24 \% \mathrm{~d}_{2}, 10 \% \mathrm{~d}_{3}$. Further fragmentation analysis on a VG70SE MS (EI, $70 \mathrm{eV})$ confirmed that most of the label was in the aromatic ring.

$\left[{ }^{2} \mathbf{H}\right]$-Resorcinol (Table 1, entry 3). Addition of substrate to the $\mathrm{Ir} / \mathrm{NaBAr}_{\mathrm{f}}$ solution was accompanied by a color change from orange to orange-brown within $20 \mathrm{~min}$. The color changed to a light yelloworange upon exposure to $\mathrm{D}_{2}$ gas. SPE solvent system: $40 \%$ EtOAc/Hexanes. Isotope distribution (Fisons VG MS): $42 \% \mathrm{~d}_{0}, 38 \% \mathrm{~d}_{1}, 13 \% \mathrm{~d}_{2}, 7 \% \mathrm{~d}_{3} .{ }^{2} \mathrm{H}$ NMR $\left(\mathrm{CH}_{3} \mathrm{OH}, 77 \mathrm{MHz}\right): \delta 4.85,6.25,6.90$. 
$\left[{ }^{2} \mathbf{H}\right]$-1-Methoxynaphthalene (Table 1, entry 4). Addition of substrate to the $\mathrm{Ir} / \mathrm{NaBAr}_{\mathrm{f}}$ solution was accompanied by a color change from orange to green-orange within $20 \mathrm{~min}$. The color changed to a light yellow-orange upon exposure to $\mathrm{D}_{2}$ gas. SPE solvent system: $40 \%$ EtOAc/Hexanes. Isotope distribution (Micromass GCT MS): $35 \% \mathrm{~d}_{0}, 39 \% \mathrm{~d}_{1}, 21 \% \mathrm{~d}_{2}, 5 \% \mathrm{~d}_{3} .{ }^{2} \mathrm{H} \mathrm{NMR}\left(\mathrm{CH}_{2} \mathrm{Cl}_{2}, 77 \mathrm{MHz}\right.$ ): $\delta 7.30-7.55$.

$\left[{ }^{2} \mathbf{H}\right]$-1-Napthoic acid (Table 1, entry 5). The solution was orange during the sequence of reactions. SPE solvent system: $30 \%$ EtOAc/Hexanes. Isotope distribution (Fisons VG MS): $41 \% \mathrm{~d}_{0}, 40 \% \mathrm{~d}_{1}$, $17 \% \mathrm{~d}_{2}, 2 \% \mathrm{~d}_{3} .{ }^{2} \mathrm{H} \mathrm{NMR}\left(\mathrm{CH}_{2} \mathrm{Cl}_{2}, 77 \mathrm{MHz}\right): \delta$ 7.58-7.72.

$\left[{ }^{2} \mathbf{H}\right]$-2-Methyl-1-nitronaphthalene (Table 1, entry 6). Addition of substrate to the $\mathrm{Ir} / \mathrm{NaBAr}_{\mathrm{f}}$ solution was accompanied by a color change from orange to red-black within 20 min. The color changed to orange upon exposure to $\mathrm{D}_{2}$ gas. SPE solvent system: $20 \%$ EtOAc/Hexanes. Isotope distribution (Fisons Trio MS): $38 \% \mathrm{~d}_{0}, 45 \% \mathrm{~d}_{1}, 17 \% \mathrm{~d}_{2}, 0 \% \mathrm{~d}_{3} .{ }^{2} \mathrm{H} \mathrm{NMR}\left(\mathrm{CH}_{2} \mathrm{Cl}_{2}, 77 \mathrm{MHz}\right): \delta 7.64,7.69$.

$\left[{ }^{2} \mathbf{H}\right]$-Methyl phenyl sulfone (Table 1 , entry 7). Addition of substrate to the $\operatorname{Ir} / \mathrm{NaBAr}_{\mathrm{f}}$ solution produced no change in color (orange) within $20 \mathrm{~min}$. The color changed to yellow upon exposure to $\mathrm{D}_{2}$ gas. Isotope distribution (Fisons VG MS): $53 \% \mathrm{~d}_{0}, 34 \% \mathrm{~d}_{1}, 9 \% \mathrm{~d}_{2}, 4 \% \mathrm{~d}_{3} .{ }^{2} \mathrm{H} \mathrm{NMR}\left(\mathrm{CH}_{2} \mathrm{Cl}_{2}, 77\right.$ MHz): $\delta 7.62,7.71$.

$\left[{ }^{2} \mathbf{H}\right]-N, N$-Dimethylaminonaphthalene (Table 1 , entry 10 ). The solution was orange during the sequence of reactions. SPE solvent system: 20\% EtOAc/Hexanes. Isotope distribution (Fisons VG MS): $61 \% \mathrm{~d}_{0}, 30 \% \mathrm{~d}_{1}, 9 \% \mathrm{~d}_{2}, 0 \% \mathrm{~d}_{3}$. Further fragmentation analysis on a VG 70SE MS (EI, $70 \mathrm{eV}$ ) proved inconclusive as to whether the label was exclusively located on the aromatic ring. There was a small amount $(<10 \%)$ of by-product in the reaction which corresponded to $\mathrm{m} / \mathrm{z} 188(\mathrm{M}+16)$ by MS, most likely an $\mathrm{N}$-oxide or similar oxidized product. 
Dimethyl(1-naphthylmethyl)amine. Formic acid (95-97\%, $320 \mu \mathrm{l})$ was added to a $5 \mathrm{ml}$ flask containing $N$-methylnaphthalene-1-methylamine (343 mg, $2.00 \mathrm{mmol}$ ) and a stir bar. The mixture was stirred until the amine had completely dissolved (exothermic). Formaldehyde (120 mg, $4 \mathrm{mmol}$ ) was then added all at once and the solution was heated at $100^{\circ} \mathrm{C}$ with continued stirring. The solution bubbled vigorously for $1 \mathrm{~min}$, and was stirred an additional $2 \mathrm{~h}$ at $90-100{ }^{\circ} \mathrm{C}$. The reaction mixture was cooled and transferred to a $30 \mathrm{ml}$ separatory funnel with $1.5 \mathrm{ml}$ water. The solution was made basic with $6 \mathrm{M} \mathrm{NaOH}$, resulting in a white, turbid solution. The aqueous solution was extracted with $\mathrm{Et}_{2} \mathrm{O}(2 \times 10 \mathrm{ml})$. The organic extracts were combined and washed with $5 \mathrm{ml}$ brine, then dried over $\mathrm{MgSO}_{4}$. The solution was filtered through a $13 \mathrm{~mm}, 0.45 \mu \mathrm{m}$ acrodisk syringe filter to remove $\mathrm{MgSO}_{4}$. Ether was evaporated to provide a slightly turbid orange oil. This oil was filtered again through a 0.2 $\mu \mathrm{m}$ syringe filter, then dried on the high vacuum line to give a clear orange oil (322 $\mathrm{mg}, 87 \%)$. This was used for the deuteration without further purification. ${ }^{1} \mathrm{H} \mathrm{NMR}\left(\mathrm{CDCl}_{3}, 400 \mathrm{MHz}\right) \delta 2.30(\mathrm{~s}, 6 \mathrm{H})$, $3.81(\mathrm{~s}, 2 \mathrm{H}), 7.38-7.43(\mathrm{~m}, 2 \mathrm{H}), 7.45-7.55(\mathrm{~m}, 2 \mathrm{H}), 7.77-7.79(\mathrm{~m}, 1 \mathrm{H}), 7.84(\mathrm{~d}, 8.5 \mathrm{~Hz}), 8.25(\mathrm{~d}, 8.5$ Hz). MS (Fisons VG, ESI): m/z $172\left(\mathrm{M}+\mathrm{H}^{+}, 57\right), 141$ (M-2Me, 100).

$\left[{ }^{2} \mathbf{H}\right]$-Dimethyl(1-naphthylmethyl)amine (Table 1, entry 11). Addition of substrate to the $\operatorname{Ir} / \mathrm{NaBAr}_{\mathrm{f}}$ solution was accompanied by a color change from orange to light green within 30 seconds, followed by a gradual return to an orange color within $20 \mathrm{~min}$. There was no color change upon exposure to $\mathrm{D}_{2}$ gas. SPE $\left(\mathrm{Al}_{2} \mathrm{O}_{3}\right)$ solvent system: $40 \%$ EtOAc/Hexanes. Isotope distribution (Fisons VG, ESI): $76 \% \mathrm{~d}_{0}$, $20 \% \mathrm{~d}_{1}, 4 \% \mathrm{~d}_{2}, 0 \% \mathrm{~d}_{3}$. MS analysis also showed that approx. $50 \%$ of the crude reaction mixture was the fully demethylated Ir-bound complex (1-naphthylmethylamine bound to $\mathrm{Cp} *\left(\mathrm{PMe}_{3}\right) \operatorname{Ir}, m / z=$ 557/559). ${ }^{2} \mathrm{H} \mathrm{NMR}\left(\mathrm{CH}_{2} \mathrm{Cl}_{2}, 77 \mathrm{MHz}\right): \delta 2.30$.

$\left[{ }^{2} \mathbf{H}\right]$-1-Naphthyl-1-ethanol (Table 1, entry 12). Addition of substrate to the $\mathrm{Ir} / \mathrm{NaBAr}_{\mathrm{f}}$ solution was accompanied by a color change from orange to dark-green/black within $20 \mathrm{~min}$. The color changed to yellow-orange upon exposure to $\mathrm{D}_{2}$ gas. SPE solvent system: 40\% EtOAc/Hexanes. The majority 
( $81 \%$ by HPLC, $\mathrm{t}_{\mathrm{R}}=12.7 \mathrm{~min}, 50 \% \mathrm{CH}_{3} \mathrm{CN}: \mathrm{H}_{2} \mathrm{O}$ ) of the substrate was converted to the ketone (1acetonaphthone), MS (VG70SE, EI, $70 \mathrm{eV}) \mathrm{m} / \mathrm{z}=170$. The remainder of the reaction mixture (19\% by HPLC, $\left.\mathrm{t}_{\mathrm{R}}=7.8 \mathrm{~min}, 50 \% \mathrm{CH}_{3} \mathrm{CN}: \mathrm{H}_{2} \mathrm{O}\right)$ was labeled 1-naphthyl-1-ethanol: isotope distribution: $42 \%$ $\mathrm{d}_{0}, 39 \% \mathrm{~d}_{1}, 16 \% \mathrm{~d}_{2}, 2 \% \mathrm{~d}_{3}$.

$\left[{ }^{2} \mathbf{H}\right]-1-A l l y l n a p h t h a l e n e$ (Table 1 , entry 13). Addition of substrate to the $\mathrm{Ir} / \mathrm{NaBAr}_{\mathrm{f}}$ solution was accompanied by a color change from orange to yellow within $20 \mathrm{~min}$. The color did not change upon exposure to $\mathrm{D}_{2}$ gas. SPE solvent system: $30 \%$ EtOAc/Hexanes. The majority of the substrate $(>90 \%)$ was transformed to more polar impurities. The most prominent impurity $\left(\sim 60 \%\right.$ by HPLC, $\mathrm{t}_{\mathrm{R}}=7.0$ min, $\left.65 \% \mathrm{CH}_{3} \mathrm{CN}: \mathrm{H}_{2} \mathrm{O}\right)$ was identified as $\mathrm{C}_{13} \mathrm{H}_{10} \mathrm{O}(\mathrm{M}+14$, most likely 1-acrylonaphthone) by HRMS (Micromass GCT, EI, $70 \mathrm{eV})$. Isotope distribution of isolated $\left[{ }^{2} \mathrm{H}\right]-1$-allylnaphthalene $\left(\mathrm{t}_{\mathrm{R}}=16.8 \mathrm{~min}\right.$, $\left.65 \% \mathrm{CH}_{3} \mathrm{CN}: \mathrm{H}_{2} \mathrm{O}\right): 82 \% \mathrm{~d}_{0}, 13 \% \mathrm{~d}_{1}, 5 \% \mathrm{~d}_{2}, 0 \% \mathrm{~d}_{3}$.

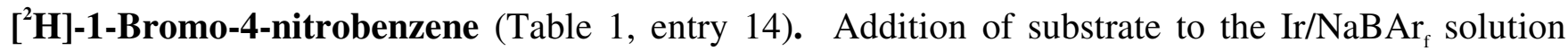
was accompanied by a color change from orange to green within $20 \mathrm{~min}$. The color changed to orange upon exposure to $\mathrm{D}_{2}$ gas. SPE solvent system: 20\% EtOAc/Hexanes. Isotope distribution (Fisons Trio, EI, $70 \mathrm{eV}$ ): $95 \% \mathrm{~d}_{0}, 5 \% \mathrm{~d}_{1}, 0 \% \mathrm{~d}_{2}, 0 \% \mathrm{~d}_{3}$.

$\left[{ }^{3} \mathbf{H}\right]$ Warfarin. The general procedure used for the other deuterated compounds was followed with the following changes. The sensitive volume $\left(\mathrm{V}_{\mathrm{e}}, 3.08 \mathrm{ml}\right)$ was loaded with 20 Torr $\mathrm{T}_{2}(3.31 \mu \mathrm{mol})$ and the manifold volume $\left(\mathrm{V}_{\mathrm{a}}\right)$ was filled with 144 Torr $\mathrm{H}_{2}$; the two chambers were quickly mixed to give a pressure of 115 Torr in $\mathrm{V}_{\mathrm{e}}\left(3.31 \mu \mathrm{mol} \mathrm{T}_{2}\right.$ and $\left.15.7 \mu \mathrm{mol} \mathrm{H}_{2}\right)$. The manifold was opened to the reaction flask and the reaction mixture was stirred for $1.5 \mathrm{~h}$ at $25{ }^{\circ} \mathrm{C}$. Exchangeable tritium was removed by adding $0.5 \mathrm{ml} \mathrm{EtOH}$ and distilling the solvents under vacuum, providing $12.3 \mathrm{mCi}$ of crude material and $65.9 \mathrm{mCi}$ exchangeable tritium. The crude material was redissolved in $250 \mu 130 \%$ EtOAc/Hexanes, and loaded onto 2 tandem $\mathrm{SiO}_{2}$ Sep-Paks ${ }^{\circledR}$ (Waters, WAT051910). The majority of the activity eluted in the $7.5-11 \mathrm{ml}$ fraction. This fraction was evaporated under an $\mathrm{N}_{2}$ stream to give 
$8.37 \mathrm{mCi}$ of $\left[{ }^{3} \mathrm{H}\right]$ warfarin (98.3\% pure by HPLC). The specific activity was determined by MS (vide supra, Sciex150, neg. ion, ESI).

II. Procedures and Characterization Data for Catalytically $d$-Labeled Compounds

General Procedure. Unless otherwise noted, reactions were manipulated in an inert atmosphere $\left(\mathrm{N}_{2}\right)$ glove box at $25{ }^{\circ} \mathrm{C}$ or using standard Schlenck techniques. Glassware was dried at $150{ }^{\circ} \mathrm{C}$ or higher for at least $12 \mathrm{~h}$. All NMR spectra were obtained using Bruker AMX $400 \mathrm{MHz}$ and DRX $500 \mathrm{MHz}$ instruments and chemical shifts are reported in parts per million $(\mathrm{ppm})$ relative to residual protiated solvent: acetone- $d_{6}(2.04) .{ }^{31} \mathrm{P}\left\{{ }^{1} \mathrm{H}\right\}$ NMR spectra were recorded at $162 \mathrm{MHz}$, and chemical shifts $(\delta)$ are reported relative to external $85 \% \mathrm{H}_{3} \mathrm{PO}_{4}$.

Material. Unless otherwise noted, reagents were purchased from commercial suppliers and used without further purification. Deuterated solvents (Cambridge Isotope Laboratories) were stored over 3 $\AA$ sieves, except $\mathrm{D}_{2} \mathrm{O}, \mathrm{CH}_{3} \mathrm{OD}$ and $\mathrm{CD}_{3} \mathrm{OD} . \quad \mathrm{Cp}^{*}\left(\mathrm{PMe}_{3}\right) \mathrm{IrCl}_{2}{ }^{3}(3)$ and $\mathrm{Cp}^{*}\left(\mathrm{PMe}_{3}\right) \operatorname{Ir}\left(\mathrm{H}_{3} \mathrm{OTf}^{4}(4)\right.$ were prepared according to literature procedures.

Catalytic H/D Exchange Experiments. In a typical reaction, a NMR tube was charged with catalyst $(3,5.0 \mathrm{mg}, 0.011 \mathrm{mmol}$ or $4,6.0 \mathrm{mg}, 0.011 \mathrm{mmol})$, substrate (see table below), solvent $(0.5 \mathrm{~mL})$ and an external standard capillary consisting of 1, 3, 5-trimethoxybenzene in $\mathrm{CD}_{2} \mathrm{Cl}_{2}{ }^{2}{ }^{2}$ The tube was attached to a Cajon adaptor, and brought out of the glovebox. The tube was put under slight vacuum $(\sim 500$ Torr) on a high vacuum line, and then flame sealed. The tube was heated in a constant temperature oil bath and the reaction was monitored by ${ }^{1} \mathrm{H}$ NMR spectroscopy through the loss of intensity of the substrate resonance. ${ }^{5}$ Deuterium incorporation was verified by ${ }^{2} \mathrm{H}$ NMR analysis. 
Reaction of 4 with benzaldehyde. The reaction was performed as described above. The organometallic product of the reaction (NMR yield: $82 \%$ ) matched the NMR data of the independently synthesized $\left[\mathrm{Cp} *\left(\mathrm{PMe}_{3}\right) \operatorname{IrPh}(\mathrm{CO})\right][\mathrm{OTf}] .{ }^{6}{ }^{1} \mathrm{H}$ NMR: (acetone- $\left.d_{6}, 400 \mathrm{MHz}\right) \delta 7.09(\mathrm{~m}, 5 \mathrm{H}, \mathrm{Ph}), 2.03$ $\left(\mathrm{s}, 15 \mathrm{H}, \mathrm{C}_{5}\left(\mathrm{CH}_{3}\right)_{5}\right), 1.79\left(\mathrm{~d}, \mathrm{P}\left(\mathrm{CH}_{3}\right)_{3}, 11.2 \mathrm{~Hz}\right) .{ }^{31} \mathrm{P}\left\{{ }^{1} \mathrm{H}\right\} \mathrm{NMR}$ : (acetone- $\left.d_{6}\right) \delta-34.5$.

Table S-1. Amount of substrate used in catalytic H/D exchange reactions.

$\begin{array}{llr}\text { amount } & \text { mmol } \\ \text { used }\end{array}$

\begin{tabular}{lll}
\hline substrate & $\begin{array}{l}\text { amount } \\
\text { used }\end{array}$ \\
\hline
\end{tabular}<smiles>COC(=O)c1ccccc1</smiles>

0.24<smiles>CN(C)C(=O)c1ccccc1</smiles>
0.22<smiles>CC(=O)Nc1ccccc1</smiles>
$26 \mathrm{mg}$ 0.22<smiles>O=C(O)CCCc1ccccc1</smiles>
2 $25 \mu \mathrm{L}$ 2 $25 \mu \mathrm{L}$ $20 \mu \mathrm{L}$ 0.25<smiles>Cc1cccc(C)n1</smiles>
0.26

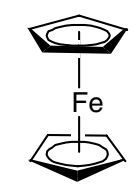

References: 
(1) Kumar, A.; Ner, D.H.; Dike, S.Y. Tetrahedron Lett. 1991, 32, 1901-1904.

(2) Kumar, A.; Ner, D.H.; Dike, S.Y. Indian J. Chem., Sect. B 1992, 31B, 803-809.

(3) Isobe, K.; Bailey, P. M.; Maitlis, P.M. J. Chem. Soc., Dalton Trans. 1981, 2003.

(4) Oldham, Warren J., Jr.; Hinkle, Amber S.; Heinekey, D. M.. J. Am. Chem. Soc. 1997, 119, 1102811036.

(5) Klei, S. R.; Tilley, T. D.; Bergman, R. G. Organometallics 2002, 21, 4905-4911.

(6) Alaimo, P. J.; Arndtsen, B. A.; Bergman, R. G.; Organometallics 2000, 19, 2130-2143. 